\title{
INFLUÊNCIA DA ADIÇÃO DE UM RESÍDUO ALCALINO DA INDÚSTRIA DE PAPEL E CELULOSE NA LIXIVIAÇÃO DE CÁTIONS EM UM SOLO ÁCIDO(1)
}

\author{
Henrique Cesar Almeida ${ }^{(2)}$, Paulo Roberto Ernani ${ }^{(3)}$, Jackson \\ Adriano Albuquerque ${ }^{(3)}$, José Mecabô Junior ${ }^{(4)} \&$ Denice Almeida $^{(2)}$
}

\section{RESUMO}

\begin{abstract}
Os subprodutos alcalinos gerados nas indústrias de papel e celulose podem ser utilizados como corretivos da acidez do solo. Entretanto, eles possuem pouco Mg e médio teor de $\mathrm{Na}$ e, por isso, podem afetar negativamente a biodisponibilidade de alguns nutrientes, assim como alguns atributos do solo. Antes de recomendálos, portanto, é importante avaliar seus efeitos. Este trabalho teve por objetivo quantificar a composição química do solo e a mobilidade vertical de cátions decorrente de formas de aplicação de um desses resíduos em relação ao calcário dolomítico. O experimento foi realizado em laboratório, sobre um Cambissolo Húmico, entre 2005 e 2006, utilizando-se colunas de lixiviação $(30$ x $10 \mathrm{~cm}$ de diâmetro). Os tratamentos consistiram de um fatorial $4 \times 2 \times 2$, incluindo dois valores prévios de pH do solo com uma testemunha cada, dois corretivos de acidez (subproduto industrial ou calcário dolomítico) e dois métodos de aplicação (superficial ou incorporado). Foram realizadas 10 percolações, espaçadas em intervalos de sete dias, num volume de $300 \mathrm{~mL}$ de água destilada por semana, totalizando o equivalente a $380 \mathrm{~mm}$ de chuva. A incorporação do resíduo industrial ao solo causou a lixiviação de $60 \%$ do $\mathrm{Na}$ adicionado, porém essa perda diminuiu para $12 \%$ quando o corretivo foi aplicado sobre a superfície. $O$ resíduo alcalino não ocasionou lixiviação de $\mathrm{Ca}, \mathrm{Mg}$ ou $\mathrm{K}$, e o calcário dolomítico lixiviou apenas $2,4 \%$ do Ca e 7,2 \% do Mg adicionados, comprovando a baixa mobilidade vertical desses cátions quando aplicados por meio de produtos alcalinos a solos com carga variável. A elevação prévia do pH diminuiu substancialmente a lixiviação dos cátions em decorrência do aumento das cargas elétricas negativas no solo. Nas condições pluviométricas da região Sul do Brasil, o $\mathrm{Na}$ adicionado pelo resíduo
\end{abstract}

\footnotetext{
(1) Parte da Dissertação de Mestrado em Ciência do Solo do primeiro autor apresentada à Universidade do Estado de Santa Catarina - UDESC. Recebido para publicação em junho de 2007 e aprovado em maio de 2008.

${ }^{(2)}$ Mestrando do Departamento de Solos da Universidade do Estado de Santa Catarina - CAV/UDESC. Caixa Postal 281, CEP 88520000 Lages (SC). Bolsista da CAPES. E-mail: henriquecav@gmail.com

${ }^{(3)}$ Professor da UDESC. Bolsista do CNPq. E-mail: a2pre@cav.udesc.br

(4) Estudante de Graduação da UDESC. Bolsista de Iniciação Científica do CNPq. E-mail: josemecabo@yahoo.com.br
} 
industrial lixiviará da camada arável em menos de um ano após sua aplicação e, portanto, não deverá prejudicar os atributos químicos e físicos do solo.

Termos de indexação: lixiviação, sódio, resíduo industrial, calcário.

\title{
SUMMARY: CATIONLEACHING FROMANACID SOIL AFTER APPLICATION OF ALKALINE BY-PRODUCT FROM THE PULP AND PAPER INDUSTRY
}

\begin{abstract}
Alkaline by-products generated in the pulp and paper industry can be used to reduce soil acidity. However, the low $\mathrm{Mg}$ and intermediate $\mathrm{Na}$ values in these residues can negatively affect the bioavailability of some nutrients and soil properties. Before recommending them, it is therefore imperative that their effects on the soil be evaluated. The objective of this study was to quantify the soil chemical composition and vertical mobility of cations due to application of alkaline industrial residue in different forms, in comparison to dolomitic limestone. The experiment was carried out in a laboratory, with a Haplumbrept, from 2005 to 2006, using leaching columns (30 x $10 \mathrm{~cm}$ diameter). The treatments consisted of a $4 \times 2 \times 2$ factorial design, including two previous values of soil $p H$ with one control each, two alkaline compounds (industrial residue or dolomitic limestone) and two application methods (surface applied or soil incorporated). Ten percolations were performed, at weekly intervals, in a volume of $300 \mathrm{~mL}$ of distilled water per week, corresponding to a total amount of $380 \mathrm{~mm}$ rain. $60 \%$ of the $\mathrm{Na}$ added leached from the soil-incorporate by-product, but this leaching decreased to $12 \%$ when it was applied on the soil surface. The addition of alkaline residue did not cause leaching of $\mathrm{Ca}, \mathrm{Mg}$ or $\mathrm{K}$, and dolomitic limestone leached only $2.4 \%$ of the Ca and $7.2 \%$ of added $\mathrm{Mg}$, demonstrating the low vertical mobility of these cations when applied from basic compounds to variable charge soils. The previous elevation of the soil $\mathrm{pH}$ decreased cation leaching substantially due to the increase of the soil negative charges. Given the rainfall conditions in southern Brazil, the amount of $\mathrm{Na}$ added will disappear from the plow layer in less than one year after its application, so this product should not negatively affect any chemical or physical soil property.
\end{abstract}

Index terms: leaching, sodium, alkaline by-product, limestone.

\section{INTRODUÇÃO}

Muitos resíduos industriais têm sido utilizados na agricultura como fonte de nutrientes ou como corretivos da acidez, principalmente porque o solo tem grande capacidade de inativar parte dos compostos adicionados por meio de vários mecanismos químicos, sobretudo de adsorção e de precipitação (Sparks, 1995). $\mathrm{O}$ descarte de resíduos no solo é uma alternativa interessante porque, ao mesmo tempo que reduz o potencial poluente desses materiais, utiliza-os como insumos agrícolas de baixo custo (Defelipo et al., 1992; Mello \& Vitti, 2002). Essa utilização, entretanto, deve ser precedida de estudos relacionados com as possíveis alterações que esses produtos possam ocasionar nas propriedades físico-químicas do solo, assim como no desenvolvimento e na composição das plantas (Ferreira et al., 2003).

Nos últimos anos, no Brasil, tem sido avaliado o efeito no solo e nas plantas de inúmeros subprodutos industriais, incluindo resíduos de curtume, de cervejaria, da exploração carbonífera, de estações de tratamento de esgoto e de indústrias de papel e celulose. Neste último, destacam-se dois resíduos: a lama de cal e o dregs. Esses subprodutos são retirados na clarificação e recuperação de produtos químicos obtidos no processo de separação da celulose (Cohn \& Ribeiro, 2002). A lama de cal possui coloração clara e é constituída basicamente por carbonatos de cálcio $\left(\mathrm{CaCO}_{3}\right)$, enquanto o dregs possui cor acinzentada e é constituído por carbonatos, hidróxidos e sulfetos, sobretudo de $\mathrm{Na}$ e de $\mathrm{Ca}$. O valor de neutralização (VN) desses resíduos normalmente varia de 40 a $70 \%$ para a lama de cal e de 39 a $78 \%$ para o dregs (Suzuki et al., 1991; Nurmesniemi et al., 2005). O dregs ainda possui aproximadamente 3,0 \% de Mg e de 1,0 a 4,0 \% de $\mathrm{Na}$ (Waldemar \& Herrera, 1986; Albuquerque et al., 2002; Nurmesniemi et al., 2005; Almeida et al., 2007), além de pequenas concentrações de $\mathrm{Ni}, \mathrm{Cd}$ e $\mathrm{Pb}$ (Nurmesniemi et al., 2005; Almeida et al., 2007).

Além de possuir alguns nutrientes essenciais às plantas e de ter a capacidade de elevar o $\mathrm{pH}$ dos solos, os resíduos alcalinos gerados pela indústria de papel e celulose têm preço muito menor do que os calcários 
comerciais, quando utilizados na mesma região de localização das unidades geradoras. Isso, sem dúvida, é um atrativo aos agricultores, devido à diminuição do custo produtivo das lavouras. A utilização de grandes quantidades desses produtos pode, no entanto, prejudicar algumas propriedades do solo, em razão da presença de Na.

A adição de $\mathrm{Na}$ ao solo pode aumentar a dispersão das argilas e dos colóides orgânicos, com prejuízos em alguns atributos físicos, como a redução da macroporosidade e o incremento do selamento superficial dos agregados (Mcintyre, 1958; Agassi et al., 1981; Reichert \& Norton, 1994; Nelson et al., 1998). Esses fenômenos acontecem porque o $\mathrm{Na}$ tem um raio hidratado grande, que dificulta sua aproximação das superfícies sólidas carregadas negativamente. Com isso, ele aumenta a espessura da dupla camada elétrica que existe ao redor das partículas do solo (van Olphen, 1977) e favorece a dispersão dos colóides. Esses efeitos negativos podem, entretanto, ser temporários, pois o $\mathrm{Na}^{+}$, por ser monovalente e ter grande raio hidratado, tem baixa afinidade pelas cargas negativas do solo relativamente aos cátions polivalentes, como $\mathrm{Al}^{3+}, \mathrm{Ca}^{2+} \mathrm{e} \mathrm{Mg}^{2+}$. Dessa forma, o Na presente na solução do solo pode ser lixiviado rapidamente para as camadas subsuperficiais, desde que haja fluxo descendente de água.

Nesse sentido, o presente trabalho teve por objetivo quantificar a mobilidade vertical de cátions no solo em função de métodos de aplicação de calcário ou de um resíduo industrial alcalino a um Cambissolo com acidez previamente corrigida ou não.

\section{MATERIAL E MÉTODOS}

O experimento foi realizado em laboratório, no Centro de Ciências Agroveterinárias (CAV) da
Universidade do Estado de Santa Catarina (UDESC), em Lages, SC, entre o segundo semestre de 2005 e o primeiro semestre de 2006.

Foram utilizadas amostras de um Cambissolo Húmico Alumínico (CHa) (Embrapa, 1999), coletadas na camada de 0 a $20 \mathrm{~cm}$ de profundidade, na localidade de Macacos, em Lages, SC. Após a coleta, o solo foi passado em peneira com malhas de $0,5 \mathrm{~cm}$ e analisado. Este solo apresentou $350 \mathrm{~g} \mathrm{~kg}^{-1}$ de argila, 360 de silte, 290 de areia, 60 de matéria orgânica e densidade de partícula de $2,54 \mathrm{~g} \mathrm{~cm}^{-3}$. A composição química do solo antes e após a aplicação dos tratamentos incorporados, porém antes das percolações, está no quadro 1. $\mathrm{Na}$ fração mineralógica havia predominância de caulinita e pequena quantidade de micas, de quartzo e de argilominerais $2: 1 \mathrm{com}$ hidróxido de alumínio nas entrecamadas (Almeida et al., 1997).

Os tratamentos foram distribuídos num delineamento inteiramente casualizado, com três repetições, e consistiram de um fatorial 4 × 2 × 2 , com dois valores prévios de $\mathrm{pH}$ do solo (incluindo uma testemunha para cada caso), dois corretivos da acidez e duas formas de aplicação destes. As unidades experimentais foram constituídas por colunas de lixiviação preenchidas com solo, confeccionadas a partir de canos de PVC, com $30 \mathrm{~cm}$ de altura e $10 \mathrm{~cm}$ de diâmetro. Cada coluna foi formada por duas porções de solo, separadas por uma tela plástica com abertura de $1,0 \mathrm{~mm}$ de diâmetro. A porção superior tinha $15 \mathrm{~cm}$ de espessura e $1,2 \mathrm{~kg}$ de solo (base seca), enquanto a inferior tinha $10 \mathrm{~cm}$ de espessura e $0,8 \mathrm{~kg}$ de solo (base seca). Os 5,0 cm superficiais de cada coluna não foram preenchidos com solo, para facilitar a adição de água. Dentro da coluna, o solo apresentava densidade média de $1,02 \mathrm{~g} \mathrm{~cm}^{-3}$ e porosidade total média de $60 \%$. A base das colunas foi hermeticamente vedada com uma tampa de PVC. Na parte central desta foi feito um orifício com 3,0 mm de diâmetro

Quadro 1. Características químicas de amostras de um Cambissolo Húmico Alumínico (CHa), com e sem correção prévia da acidez, após a incorporação de um resíduo alcalino da indústria de papel e celulose e de calcário dolomítico

\begin{tabular}{|c|c|c|c|c|c|c|}
\hline Tratamento & $\mathrm{pH}-\mathrm{H}_{2} \mathrm{O}$ & $\mathbf{K}^{+}$ & $\mathrm{Na}^{+}$ & $\mathrm{Ca}^{2+}$ & $\mathrm{Mg}^{2+}$ & $\mathrm{Al}^{3+}$ \\
\hline & & - & $\mathrm{mg} \mathrm{kg}^{-1}-$ & $\longrightarrow$ & $\mathrm{ol}_{\mathrm{c}} \mathrm{kg}^{-1}$ & - \\
\hline \multicolumn{7}{|c|}{ Sem calagem prévia } \\
\hline Testemunha & 4,4 & 158 & 7 & 1,5 & 0,9 & 5,1 \\
\hline Calcár io incorporado & 6,2 & 157 & 10 & 9,0 & 6,3 & 0,0 \\
\hline Resíduo incorporado & 6,4 & 160 & 197 & 15,4 & 1,2 & 0,0 \\
\hline \multicolumn{7}{|c|}{ Com calagem prévia } \\
\hline Testemunha & 6,2 & 157 & 10 & 9,0 & 6,3 & 0,0 \\
\hline Calcário incorporado & 7,5 & 153 & 11 & 16,0 & 13,0 & 0,0 \\
\hline Resíduo incorporado & 7,6 & 157 & 140 & 24,0 & 7,0 & 0,0 \\
\hline
\end{tabular}


para permitir a drenagem da solução percolada, sobre o qual, internamente, foi colocada tela plástica com malha de $1,0 \mathrm{~mm}$ de abertura, a fim de evitar a passagem de solo. Cada coluna foi envolta com um funil plástico flexível, confeccionado a partir de sacos plásticos transparentes, a fim de evitar a perda de efluente e direcionar a solução percolada para os frascos de coleta, localizados abaixo delas.

A elevação prévia do $\mathrm{pH}$ de metade das amostras de solo foi efetuada seis meses antes do preenchimento das colunas. Para isso, $10 \mathrm{~g} \mathrm{~kg}^{-1}$ de calcário dolomítico foram misturados e homogeneizados com as amostras. Os dois corretivos de acidez (resíduo industrial e calcário dolomítico) foram aplicados por ocasião da transferência do solo para as colunas de lixiviação. Cada um deles foi adicionado sobre a superfície das colunas (método superficial) ou misturado (método incorporado) com todo o volume de solo da parte superior delas. No método de aplicação superficial, a fim de evitar a formação de crostas calcárias na superfície do solo, os corretivos da acidez foram misturados manualmente e homogeneizados com $80 \mathrm{~g}$ de solo (base seca), cujo volume foi depositado na parte mais superficial de cada coluna e correspondeu a uma camada com 1,0 cm de espessura. As quantidades adicionadas do resíduo industrial (15 g por coluna) ou de calcário dolomítico (12 g por coluna) foram as mesmas para as duas formas de aplicação (superficial ou incorporada) e corresponderam a uma vez a dose $(\mathrm{PRNT}=100 \%)$ recomendada pelo método SMP para elevar para 6,0 o $\mathrm{pH}$ das amostras sem calagem prévia.

O resíduo industrial utilizado apresentava $\mathrm{Ca}=$ $354 \mathrm{~g} \mathrm{~kg}^{-1}, \mathrm{Mg}=9,2 \mathrm{~g} \mathrm{~kg}^{-1}, \mathrm{Na}=10,2 \mathrm{~g} \mathrm{~kg}^{-1}, \mathrm{pH}=$ 10,7 , valor de neutralização $(\mathrm{VN})=80 \%$ e eficiência relativa (ER) de $100 \%$ (Almeida et al., 2007). O calcário dolomítico apresentava $\mathrm{Ca}=289 \mathrm{~g} \mathrm{~kg}^{-1}, \mathrm{Mg}$ $=118 \mathrm{~g} \mathrm{~kg}^{-1}, \mathrm{Na}=170 \mathrm{mg} \mathrm{kg}^{-1}, \mathrm{VN}=99,7 \%$ e ER de $100 \%$. Os teores de $\mathrm{Ca}$, de $\mathrm{Mg}$ e de $\mathrm{Na}$ do calcário, além do seu VN e ER, foram determinados de acordo com o método descrito em Tedesco et al. (1995).

Após serem preenchidas com o solo, as colunas foram acondicionadas verticalmente em suportes plásticos, cuja base ficou $20 \mathrm{~cm}$ acima da superfície de um balcão. As percolações iniciaram-se uma semana após a transferência do solo para as colunas. Elas foram repetidas a cada sete dias, durante 10 semanas. Em cada percolação, adicionaram-se $300 \mathrm{~mL}$ de água destilada sobre a superfície de cada coluna, na velocidade de $2,0 \mathrm{~mL}$ por minuto, totalizando o equivalente a $380 \mathrm{~mm}$ de chuva durante todo o período experimental. A solução percolada foi coletada no dia seguinte, para determinação do volume e da composição química.

Na solução percolada, foram determinados o $\mathrm{pH}$, a condutividade elétrica (CE) e as concentrações de Ca, $\mathrm{Mg}, \mathrm{K}$ e Na. No solo da coluna, foram avaliados o pH$\mathrm{H}_{2} \mathrm{O}$ e os teores de $\mathrm{Ca}, \mathrm{Mg}, \mathrm{K}, \mathrm{Na}$ e Al trocáveis. As concentrações de $\mathrm{Ca}$ e de $\mathrm{Mg}$ foram quantificadas por espectrofotometria de absorção atômica; K e Na, por fotometria de emissão; $\mathrm{pH}$, por potenciometria; $\mathrm{Al}$ trocável, por titulometria ácido-base; e CE, por condutivimetria. Os métodos utilizados estão descritos em Tedesco et al. (1995).

Os resultados foram submetidos à análise de variância por meio dos modelos geométricos lineares (procedimento GLM). As médias foram comparadas por meio de contraste a $5 \%$ de significância.

\section{RESULTADOS E DISCUSSÃO}

\section{Efeitos no sódio}

A lixiviação de Na variou com o corretivo da acidez (resíduo industrial ou calcário dolomítico), com a forma de aplicação deste e com o pH prévio do solo (Quadro 2). Ela foi maior com o resíduo industrial do que com calcário, principalmente quando o resíduo foi incorporado ao solo (Figura 1). O calcário não lixiviou $\mathrm{Na}$, independentemente da forma de aplicação e dos valores prévios de $\mathrm{pH}$ do solo (Quadro 2), devido à pequena concentração do elemento nesse produto (170 $\mathrm{mg} \mathrm{kg}^{-1}$ ). A dose de calcário utilizada, apesar de alta (10 $\mathrm{g} \mathrm{kg}^{-1}$ de solo ou $20 \mathrm{~g}$ por coluna), adicionou apenas 3,4 mg de $\mathrm{Na}$ por coluna, o que equivale a $1,7 \mathrm{mg} \mathrm{kg}^{-1}$ de solo. Azevedo et al. (1996) aplicaram doses de até $40 \mathrm{Mg} \mathrm{ha}^{-1}$ de calcário dolomítico a um Latossolo Bruno e verificaram que nessa dose a concentração de Na da camada superficial com $20 \mathrm{~cm}$ de profundidade aumentou apenas $1,9 \mathrm{mmol}_{\mathrm{c}} \mathrm{kg}^{-1}$.

Grande parte do $\mathrm{Na}$ adicionado pelo resíduo industrial lixiviou em pouco tempo, porém a magnitude da lixiviação variou com a forma de aplicação e com os valores prévios de $\mathrm{pH}$ (Quadro 2, Figura 1). A maior lixiviação de $\mathrm{Na}$ aconteceu quando o resíduo industrial foi incorporado ao solo nas amostras sem calagem prévia. Nesse tratamento, em apenas 10 percolações de água, o resíduo industrial lixiviou $150 \mathrm{mg}$ dos $255 \mathrm{mg}$ de $\mathrm{Na}$ adicionados por coluna, totalizando $60 \%$ do aplicado. A maior lixiviação de $\mathrm{Na}$ ocorreu na oitava percolação, cuja concentração máxima atingiu $154 \mathrm{mg} \mathrm{L}^{-1}$ no efluente percolado (Figura 2). Considerando que a precipitação média anual no Planalto Catarinense é de aproximadamente $1.550 \mathrm{~mm}$, estima-se que todo o $\mathrm{Na}$ adicionado pela dose de $20 \mathrm{Mg}_{\text {ha }}{ }^{-1}$ do resíduo seja lixiviado em menos de um ano, caso o produto seja incorporado ao solo, pois neste trabalho as percolações equivaleram a uma precipitação total de $380 \mathrm{~mm}$ de chuva. Quando o resíduo industrial foi aplicado nas amostras de solo que já tinham recebido calagem, a lixiviação de $\mathrm{Na}$ diminuiu $22 \%$ em relação ao solo sem correção prévia de $\mathrm{pH}$, devido, provavelmente, ao aumento do número de cargas elétricas negativas geradas pelo aumento do pH (Albuquerque et al., 2000).

Quando o resíduo industrial foi aplicado sobre a superfície do solo que não havia recebido correção 
Quadro 2. Análise da diferença entre os valores acumulados de $\mathrm{Na}, \mathrm{K}, \mathrm{Ca}$ e Mg após 10 percolações em amostras de um Cambissolo Húmico com dois valores prévios de pH em conseqüência da aplicação de um resíduo industrial da indústria de papel e celulose ou de calcário dolomítico

\begin{tabular}{|c|c|c|c|c|}
\hline Contraste & $\mathrm{Na}$ & $\mathbf{K}$ & $\mathbf{C a}$ & Mg \\
\hline & & & \multirow{2}{*}{$\mathrm{mg} \underset{*(+)}{*_{(+)}}$} & \multirow{2}{*}{$*_{(+)}$} \\
\hline Calcário Inc x Calcário $\operatorname{Sup}^{(1)}(\mathrm{s} / \mathrm{c})$ & ns & ns & & \\
\hline Resíduo Inc x Resíduo Sup (s/c) ${ }^{(2)}$ & $*(+)$ & ns & $\mathrm{ns}$ & $\mathrm{ns}$ \\
\hline Calcá rio Inc x Resíduo Inc (s/c) & $*(-)$ & $*(+)$ & $*(+)$ & $*(+)$ \\
\hline Calcário Sup x Resíduo Sup (s/c) & $\mathrm{ns}$ & $\mathrm{ns}$ & $\mathrm{ns}$ & $\mathrm{ns}$ \\
\hline Testemunha x Calcário Inc (s/c) & ns & $*(-)$ & $*_{(-)}$ & $*()$. \\
\hline Testemunha x Calcário Sup (s/c) & $\mathrm{ns}$ & $\mathrm{ns}$ & $\mathrm{ns}$ & $\mathrm{ns}$ \\
\hline Testemunha x Resíduo Inc (s/c) & $*()$. & $\mathrm{ns}$ & $\mathrm{ns}$ & $\mathrm{ns}$ \\
\hline Testemunha x Resídu o Sup (s/c) & $\mathrm{ns}$ & $\mathrm{ns}$ & ns & ns \\
\hline Calcário Inc x Calcário Sup (c/c) & $\mathrm{ns}$ & ns & $\mathrm{ns}$ & ns \\
\hline Resíduo Inc x Resíduo Sup (c/c) & $*(+)$ & ns & $\mathrm{ns}$ & $\mathrm{ns}$ \\
\hline Calcário Inc x Dregs Inc (c/c) & $*(-)$ & $\mathrm{ns}$ & ns & $\mathrm{ns}$ \\
\hline Calcário Sup x Resíduo Sup (c/c) & $\mathrm{ns}$ & ns & $\mathrm{ns}$ & $\mathrm{ns}$ \\
\hline Testemunha x Calcário Inc (c/c) & ns & ns & $\mathrm{ns}$ & $*(-)$ \\
\hline Testemunha x Calcário Sup (c/c) & $\mathrm{ns}$ & ns & ns & $\mathrm{ns}$ \\
\hline Testemunha x Resíduo Inc (c/c) & $*(\cdot)$ & ns & $\mathrm{ns}$ & $*(\cdot)$ \\
\hline Testemunha x Resíduo Sup (c/c) & $\mathrm{ns}$ & ns & $\mathrm{ns}$ & $\mathrm{ns}$ \\
\hline \multirow[t]{2}{*}{$(\mathrm{s} / \mathrm{c}) \times(\mathrm{c} / \mathrm{c})$} & $*(+)$ & *(+) & *(-) & *(-) \\
\hline & \multicolumn{4}{|c|}{ Resumo da análise de variância do procedimento GLM } \\
\hline $\mathrm{R}^{2}$ & 0,92 & 0,98 & 0,93 & 0,98 \\
\hline CV (\%) & 42 & 7,3 & 17 & 17 \\
\hline
\end{tabular}

(1) inc: produtos incorporados ao solo; sup: produtos aplicados sobre a superfície do solo. ${ }^{(2)}$ s/c: solo sem correção prévia do pH; c/ c: solo com correção prévia do $\mathrm{pH}$. *: significativo a $5 \%$ pelo teste de Student, segundo análise de contraste. Valores positivos mostram maior diferença significativa do grupo à esquerda do contraste, enquanto os valores negativos mostram maior diferença significativa do grupo à direita do contraste; ns: não-significativo.

prévia de $\mathrm{pH}$, a perda de $\mathrm{Na}$ foi de apenas $12 \%$ do adicionado, ou seja, cerca de cinco vezes menos do que no tratamento incorporado (Figura 1). O efeito mais lento proporcionado pela aplicação superficial fez com que a maior perda de $\mathrm{Na}$ ocorresse somente entre a oitava e a décima percolação, com concentração máxima de $50 \mathrm{mg} \mathrm{L}^{-1}$ na solução percolada (Figura 2). $\mathrm{Na}$ média dos tratamentos com o resíduo industrial (com e sem correção prévia de pH), a incorporação desse subproduto alcalino lixiviou $92 \mathrm{mg}$ a mais de $\mathrm{Na}$ por coluna em relação aos tratamentos com aplicação sobre a superfície do solo (Figura 1), o que representa $36 \%$ do $\mathrm{Na}$ adicionado. Quando aplicado sobre a superfície do solo, o produto precisa percorrer um caminho mais longo até atingir o fundo da coluna, sendo, portanto, fortemente dependente da quantidade de água que percola através do perfil do solo, ou seja, da intensidade e da quantidade das chuvas.

O Na remanescente no solo após o término das percolações variou com a forma de aplicação do resíduo industrial. Nas amostras de solo coletadas da parte superior da coluna $(15 \mathrm{~cm})$, a adição do resíduo industrial numa quantidade equivalente a $20 \mathrm{Mg} \mathrm{ha}^{-1}$ manteve uma concentração de $\mathrm{Na}$ de $138 \mathrm{mg} \mathrm{kg}^{-1}$ quando o produto foi incorporado e de $230 \mathrm{mg} \mathrm{kg}-1$ quando ele foi aplicado sobre a superfície do solo, na média das amostras com e sem calagem prévia. Na testemunha e nos tratamentos com calcário dolomítico, a concentração de $\mathrm{Na}$ foi de 7 e de $10 \mathrm{mg} \mathrm{kg}^{-1}$, respectivamente (dados não mostrados).

\section{Efeitos no cálcio e no magnésio}

Os dois corretivos da acidez provocaram pouca lixiviação de $\mathrm{Ca}$ e de $\mathrm{Mg}$ (Quadro 2, Figuras 3 e 4). A adição de calcário dolomítico, numa dose equivalente a $20 \mathrm{Mg} \mathrm{ha}^{-1}\left(10 \mathrm{~g} \mathrm{~kg}^{-1}\right)$, lixiviou somente $2,4 \%$ do Ca e 7,2 \% do $\mathrm{Mg}$ adicionados. Essa pequena lixiviação se deve à baixa solubilidade dos calcários agrícolas, aliada às pequenas quantidades de seus ânions que permanecem na solução do solo após a correção da acidez (Ernani et al., 2001; Miranda et al., 2005). É necessário considerar, entretanto, que a quantidade de água percolada pelas 10 adições foi relativamente pequena-o equivalente a um total de $380 \mathrm{~mm}$ de chuva.

A lixiviação desses dois cátions foi tão pequena a ponto de a adição de $25 \mathrm{Mg} \mathrm{ha}^{-1}\left(12,5 \mathrm{~g} \mathrm{~kg}^{-1}\right)$ do resíduo industrial, que tem $354 \mathrm{~g} \mathrm{~kg}^{-1}$ de Ca, não ter afetado 


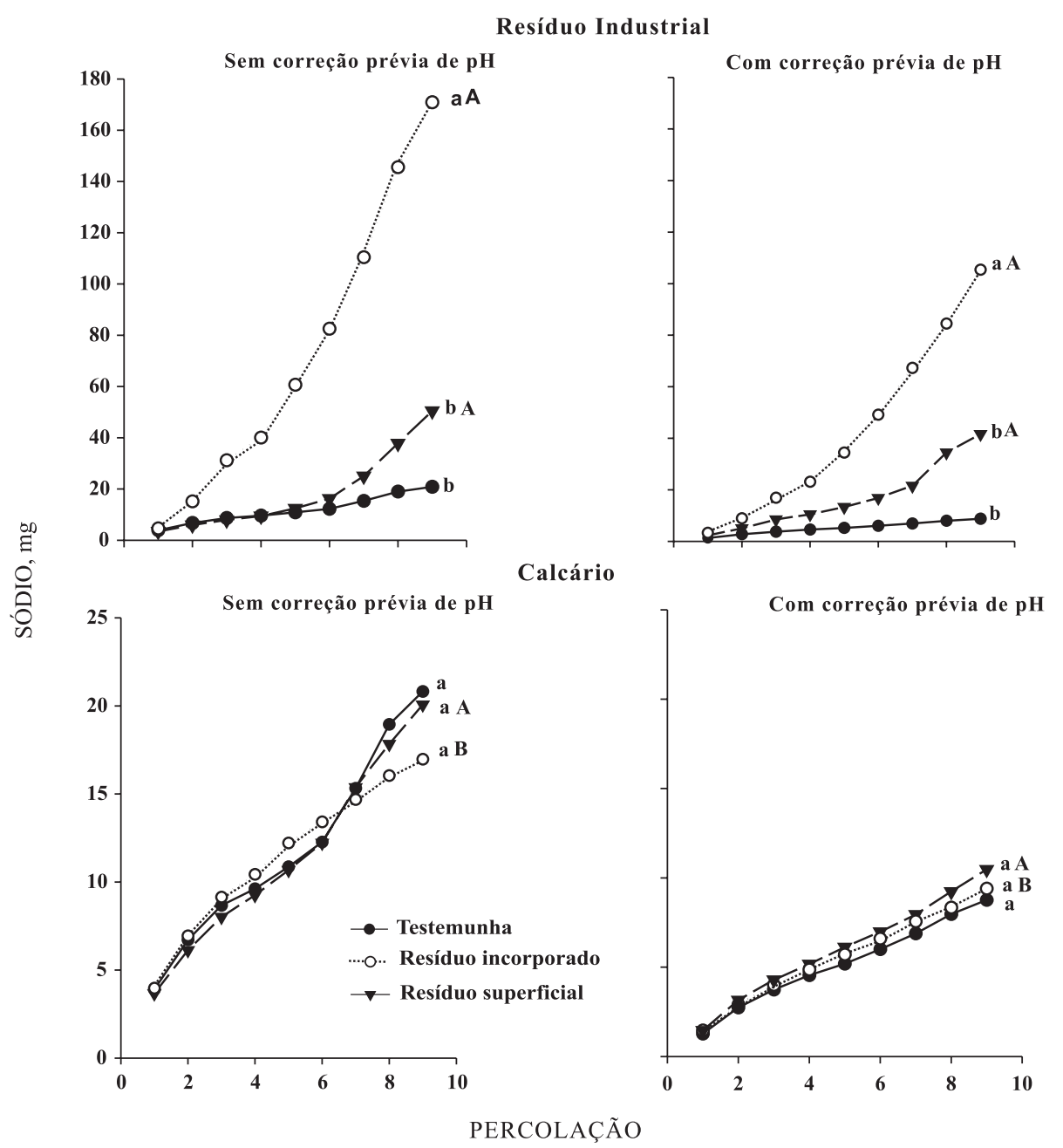

Figura 1. Perdas acumuladas de sódio após 10 percolações com água destilada em conseqüência da aplicação de calcário ou de um resíduo industrial em amostras de solo com e sem correção prévia de pH. (Letras minúsculas comparam as formas de aplicação de cada corretivo com a testemunha dentro de cada pH; letras maiúsculas comparam esses mesmos tratamentos entre os corretivos da acidez, dentro do mesmo pH. Ausência de letra significa inexistência de diferença estatística pela análise de contraste a $5 \%$ ).

a perda desse nutriente, independentemente da forma de aplicação, em relação ao tratamento em que ele não foi aplicado (Quadro 2). Na média dos tratamentos, aqueles com correção prévia da acidez foram os que causaram maior lixiviação de $\mathrm{Ca}$ e de Mg (Quadro 2), em razão da existência de maiores concentrações desses dois cátions, tanto nas cargas negativas como na solução do solo (Ciotta et al., 2004). Além disso, os tratamentos com correção prévia da acidez possuíam distribuição uniforme de calcário dolomítico em toda a extensão da coluna, o que facilita a lixiviação desses íons. Nos tratamentos sem calagem prévia, os corretivos foram aplicados na superfície do solo ou incorporados nos $15 \mathrm{~cm}$ superficiais, dependendo do tratamento, e, para atingirem o fundo da coluna, teriam que percorrer pelo menos mais $10 \mathrm{~cm}$ de solo. Como a coluna tinha $25 \mathrm{~cm}$ de solo e o resíduo industrial foi aplicado sobre a superfície ou misturado com os $15 \mathrm{~cm}$ da parte superior, verifica-se, portanto, que a mobilidade vertical do Ca originário desse resíduo industrial foi inferior a $10 \mathrm{~cm}$. Esses dados confirmam a baixa mobilidade dos cátions adicionados pelos corretivos da acidez, constantemente verificada nos solos do Sul do Brasil (Ernani et al., 2001, 2004).

A incorporação dos dois corretivos da acidez (resíduo alcalino ou calcário dolomítico) às amostras com correção prévia de $\mathrm{pH}$ lixiviou aproximadamente $30 \mathrm{mg}$ a mais de $\mathrm{Mg}$ do que de $\mathrm{Ca}$ (Figuras 3 e 4). A maior solubilidade do $\mathrm{MgCO}_{3}$ em relação ao $\mathrm{CaCO}_{3}$ presentes no calcário dolomítico adicionado previamente nessas amostras e a menor preferência do Mg em relação ao Ca pelas cargas negativas (Ernani \& Barber, 1996) provavelmente foram as responsáveis pela maior lixiviação do $\mathrm{Mg}$ ao longo da coluna de solo. As constantes de solubilidade $\left(\mathrm{K}_{\mathrm{ps}}\right)$ do $\mathrm{CaCO}_{3}$ e do $\mathrm{MgCO}_{3}$ são, respectivamente, de 4,8 x $10^{-9}$ e $2,6 \times 10^{-5}$ (Weast, 1972). 


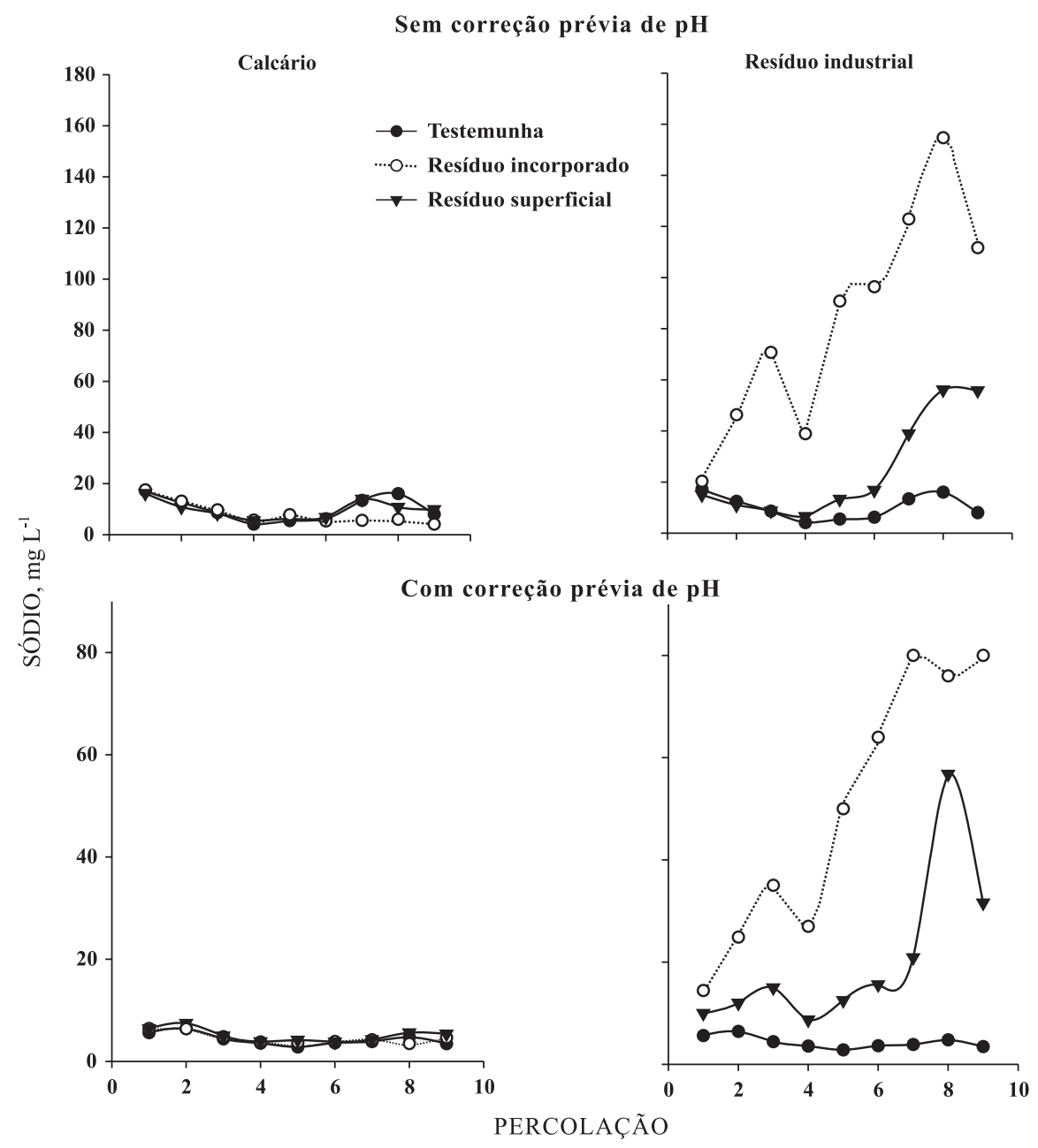

Figura 2. Flutuação temporal da concentração de sódio na solução percolada em cada uma das 10 percolações com água destilada em função de formas de aplicação de calcário ou de um resíduo industrial em amostras de solo com e sem correção prévia de pH.

\section{Efeitos no potássio e no pH}

A maior lixiviação de K ocorreu nas amostras de solo sem prévia elevação do pH (Quadro 2), numa média de $36 \mathrm{mg}$ por coluna a mais do que nas amostras que receberam calcário previamente (Figura 5), onde foram retidos, em média, cerca de $130 \mathrm{mg} \mathrm{kg}^{-1}$ de $\mathrm{K}$. Como a elevação do $\mathrm{pH}$ aumenta o número de cargas elétricas negativas do solo (Albuquerque et al., 2000), parte do K da solução passa a ser adsorvida eletrostaticamente às cargas criadas e se torna menos suscetível à lixiviação (Ernani et al., 2001, 2007). Em virtude da diminuição da concentração de $\mathrm{K}$ na solução, decorrente do aumento das cargas negativas, a nova tabela de adubação dos Estados do Rio Grande do Sul e de Santa Catarina considera a capacidade de troca de cátions (CTC) do solo como um fator na avaliação da disponibilidade de K às plantas (CFSRS/ SC, 2004).
Relativamente à testemunha, nenhum tratamento com o resíduo industrial ocasionou lixiviação de $\mathrm{K}$. O calcário dolomítico, entretanto, somente lixiviou K quando foi incorporado ao solo nos tratamentos sem prévia elevação do $\mathrm{pH}$ (Quadro 2, Figura 5). A concentração de $\mathrm{Na}$ presente no resíduo industrial não afetou, portanto, o equilíbrio do K no solo, nas condições experimentais utilizadas no presente estudo. A maior lixiviação de $\mathrm{K}$ provocada pelo calcário dolomítico em relação ao resíduo industrial se deveu, provavelmente, à maior quantidade total de cátions divalentes $(\mathrm{Ca}+\mathrm{Mg})$ no calcário, os quais possuem maior afinidade pelas cargas negativas do solo em relação aos cátions monovalentes. Quando os corretivos da acidez são aplicados ao solo, esses dois cátions descem até profundidades maiores do que aquelas onde ocorre elevação do pH (Ernani et al., 2004). Com isso, parte dos átomos de $\mathrm{Ca}$ e de $\mathrm{Mg}$ que atinge as profundidades onde o $\mathrm{pH}$ não foi afetado desloca $\mathrm{K}$ das 


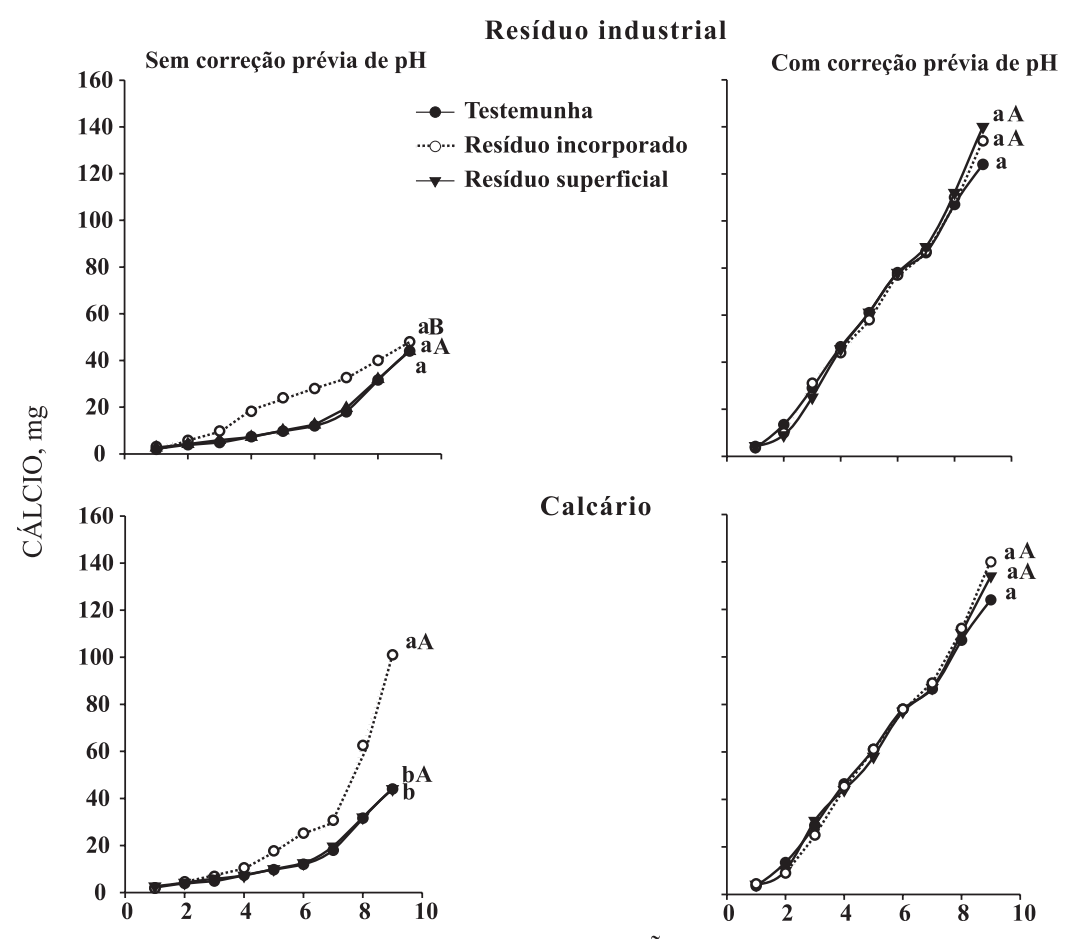

Figura 3. Perdas acumuladas de cálcio após 10 percolações com água destilada em decorrência da aplicação de calcário ou de um resíduo industrial em amostras de solo com e sem correção prévia de pH. (Letras minúsculas comparam as formas de aplicação de cada corretivo com a testemunha dentro de cada pH; letras maiúsculas comparam esses mesmos tratamentos entre os corretivos da acidez, dentro do mesmo pH. Ausência de letra significa inexistência de diferença estatística pela análise de contraste a $5 \%$ ).

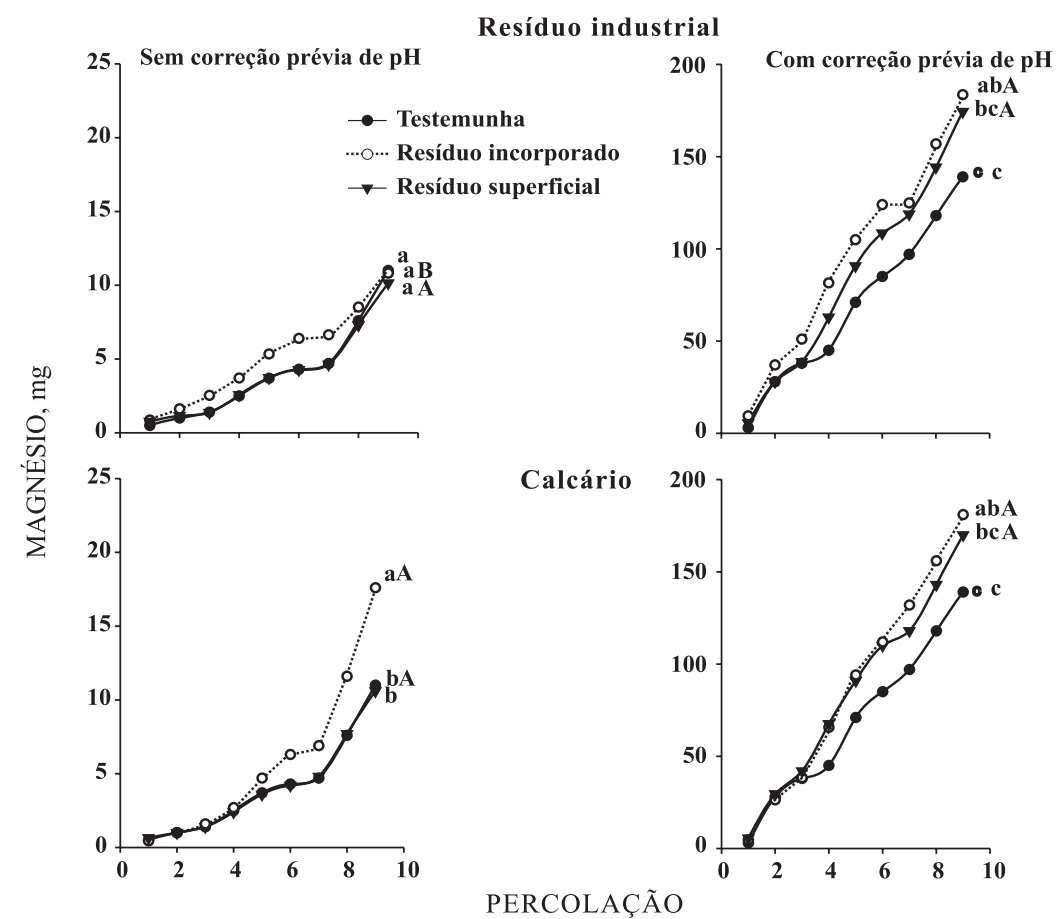

Figura 4. Perdas acumuladas de magnésio após 10 percolações de água destilada em conseqüência da aplicação de calcário ou de um resíduo industrial em amostras de solo com e sem correção prévia de pH. (Letras minúsculas comparam as formas de aplicação de cada corretivo com a testemunha dentro de cada pH; letras maiúsculas comparam esses mesmos tratamentos entre os corretivos da acidez, dentro do mesmo pH. Ausência de letra significa inexistência de diferença estatística pela análise de contraste a $5 \%$ ). 
cargas elétricas dessa região para a solução do solo, facilitando sua lixiviação. Ernani et al. (2004) verificaram resultados semelhantes com o deslocamento do $\mathrm{Al}^{3+}$ nas camadas de solo abaixo dos locais de aplicação de calcário. Nos tratamentos em que o pH do solo foi corrigido previamente esse fenômeno não aconteceu, devido à uniformidade na distribuição do calcário em toda a extensão da coluna de solo. A concentração de $\mathrm{K}$ tanto no calcário quanto no resíduo alcalino foi inferior a $1,5 \mathrm{mg} \mathrm{kg}^{-1}$.

$\mathrm{O}$ pH do efluente percolado das colunas de solo, na média das 10 percolações, não foi afetado pela adição dos corretivos da acidez (calcário e o resíduo industrial) nem pelos métodos de incorporação destes (superficial ou incorporado). A incorporação dos corretivos da acidez nas amostras de solo aumentou o $\mathrm{pH}$ de 4,4 para 6,3 , nos tratamentos sem calagem prévia, e de 6,2 para 7,55 , naqueles com calagem prévia (Quadro 1). $\mathrm{O} \mathrm{pH}$ da solução percolada não foi afetado pelos tratamentos porque o efeito alcalino exercido pelos corretivos da acidez na parte superior da coluna foi contrabalanceado pelo efeito acidificante ocasionado pela hidrólise do $\mathrm{Al}^{3+}$, retirado das cargas negativas do solo abaixo das regiões corrigidas pelo Ca e pelo Mg (Ernani et al., 2004).

\section{CONCLUSÃO}

A lixiviação do $\mathrm{Na}$ adicionado ao solo pelo resíduo alcalino da indústria de papel e celulose diminuiu com o aumento do $\mathrm{pH}$ e foi afetada pela forma de aplicação. Ela variou de 12 a $60 \%$ do total adicionado, respectivamente quando esse subproduto industrial foi adicionado sobre a superfície ou incorporado na camada superficial do solo. Por sua vez, o resíduo não lixiviou K, Ca e Mg. Com base nessas avaliações laboratoriais, presume-se que esse produto possa ser utilizado como corretivo da acidez para solos ácidos sem ocasionar efeitos negativos nas propriedades químicas e físicas.

\section{LITERATURA CITADA}

AGASSI, M.; SHAINBERG, I. \& MORIN, J. Effects of electrolyte concentration and soil sodicity on infiltration rate and crust formation. Soil Sci. Soc. Am. J., 45:848$851,1981$.

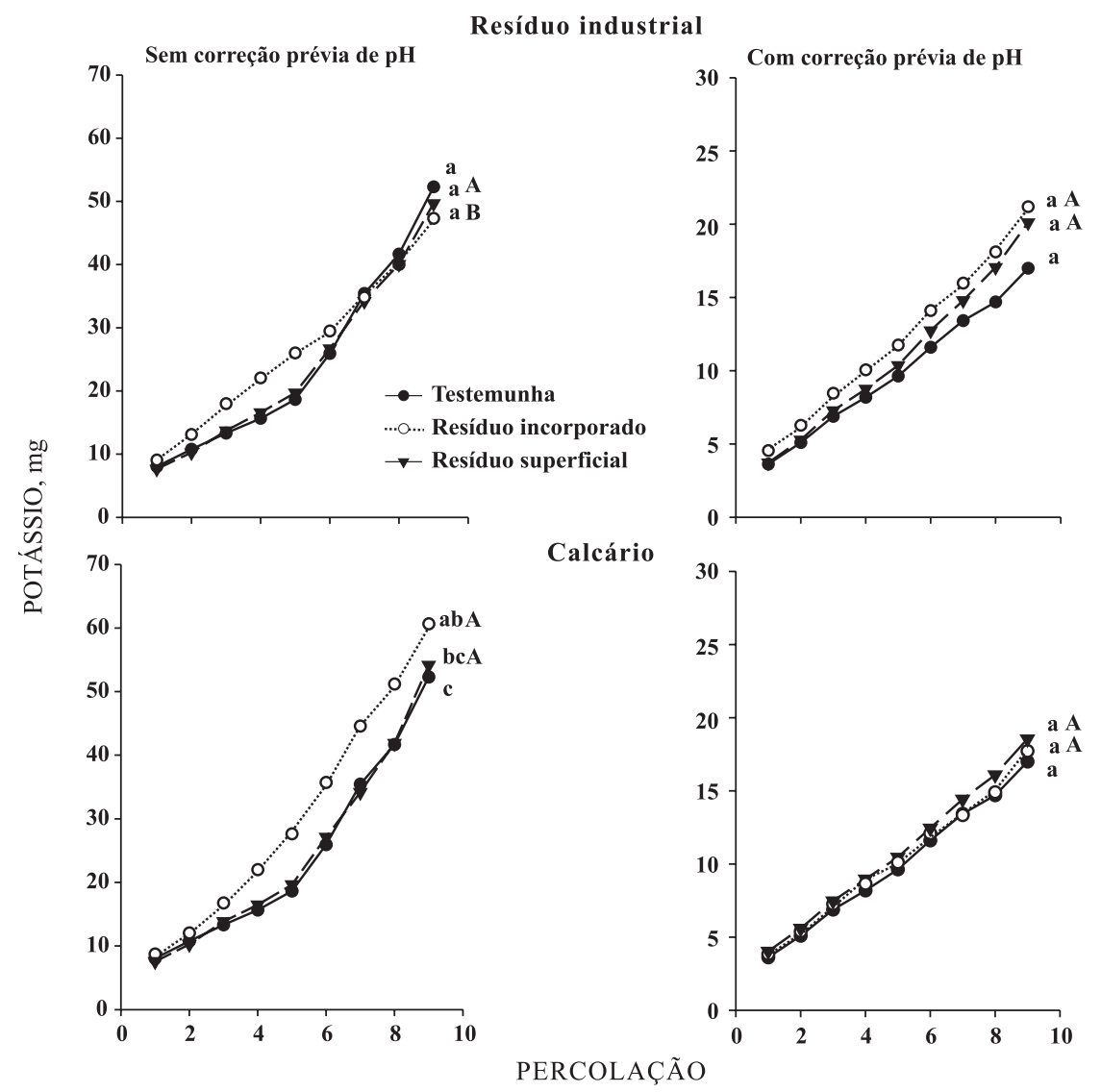

Figura 5. Perdas acumuladas de potássio após 10 percolações com água destilada em virtude da aplicação de calcário ou de um resíduo industrial em amostras de solo com e sem correção prévia de pH. (Letras minúsculas comparam as formas de aplicação de cada corretivo com a testemunha dentro de cada pH; letras maiúsculas comparam esses mesmos tratamentos entre os corretivos da acidez, dentro do mesmo pH. Ausência de letra significa inexistência de diferença estatística pela análise de contraste a 5 \%). 
ALBUQUERQUE, J.A.; BAYER, C.; ERNANI, P.R. \& FONTANA, E.C. Propriedades físicas e eletroquímicas de um Latossolo Bruno afetadas pela calagem. R. Bras. Ci. Solo, 24:295-300, 2000.

ALBUQUERQUE, J.A.; ARGENTON, J.; FONTANA, E.C.; COSTA, F.S. \& RECH, T.D. Propriedades físicas e químicas de solos incubados com resíduo alcalino da indústria de celulose. R. Bras. Ci. Solo, 26:1065-1073, 2002.

ALMEIDA, H.C.; SILVEIRA, C.B.; ERNANI, P.R.; CAMPOS, M.L. \& ALMEIDA, D. Composição química de um resíduo alcalino da indústria de papel e celulose (dregs). Química Nova, 30:1669-1672, 2007.

ALMEIDA, J.A.; KÄMPF, N. \& ALMEIDA, R. Caracterização mineralógica de Cambissolos originados de rochas pelíticas nos patamares do alto rio Itajaí e no planalto de Lages. $R$. Bras. Ci. Solo, 21:181-190, 1997.

AZEVEDO, A.C.; KÄMPF, N. \& BOHNEN, H. Alterações na dinâmica evolutiva de Latossolo Bruno pela calagem. R. Bras. Ci. Solo, 20:191-199, 1996.

CIOTTA, M.N.; BAYER, C.; ERNANI, P.R.; FONTOURA, S.M.V.; WOBETO, C. \& ALBUQUERQUE, J.A. Manejo da calagem e os componentes da acidez de Latossolo Bruno em plantio direto. R. Bras. Ci. Solo, 28:317-326, 2004.

COHN, P.E. \& RIBEIRO, R.N. Medição "on line" do alcali total nos licores branco e verde empregando tecnologia FTNIR. In: CONGRESSO E EXPOSIÇÃO ANUAL DE CELULOSE E PAPEL, 25., São Paulo, 2002. Trabalhos Técnicos... São Paulo, 2002. p.1-10.

COMISSÃO DE FERTILIDADE DO SOLO - CFSRS/SC. Recomendações de adubação e de calagem para os Estados do Rio Grande do Sul e de Santa Catarina. 4.ed. Passo Fundo, Sociedade Brasileira de Ciência do Solo, 2004. $412 \mathrm{p}$.

DEFELIPO, B.V.; NOGUEIRA, A.V.; LOURES, E.G. \& ALVAREZ V., V.H. Eficiência agronômica de um resíduo de indústria siderúrgica. R. Bras. Ci. Solo, 16:127-131, 1992.

EMPRESA BRASILEIRA DE PESQUISA AGROPECUÁRIA EMBRAPA. Centro Nacional de Pesquisa de Solos. Sistema brasileiro de classificação de solos. Brasília, Serviço de Produção e Informação, 1999. 412p.

ERNANI, P.R. \& BARBER, S.A. The effect of ionic strength on soil $\mathrm{P}$ reactions is negligible. Fert. Res., 45:193-197, 1996.

ERNANI, P.R.; RIBEIRO, M.S. \& BAYER, C. Modificações químicas em solos ácidos ocasionadas pelo método de aplicação de corretivos da acidez e de gesso agrícola. Sci. Agric., 58:825-831, 2001.

ERNANI, P.R.; RIBEIRO, M.F.S. \& BAYER, C. Chemical modifications caused by liming below the limed layer in a predominantly variable charge acid soil. Comm. Soil Sci. Plant Anal., 35:889-901, 2004.
ERNANI, P.R.; BAYER, C.; ALMEIDA, J.A. \& CASSOL, P.C. Mobilidade vertical de cátions influenciada pelo método de aplicação de cloreto de potássio em solos com carga variável. R. Bras. Ci. Solo, 31:393-402, 2007.

FERREIRA, A.S.; CAMARGO, F.A.O.; TEDESCO, M.J. \& BISSANI, C.A. Alterações de atributos químicos e biológicos de solo e rendimento de milho e soja pela utilização de resíduos de curtume e carbonífero. R. Bras. Ci. Solo, 27:755-763, 2003.

MELLO, S.C. \& VITTI, G.C. Influência de materiais orgânicos no desenvolvimento do tomateiro e nas características químicas do solo em ambiente protegido. Hortic. Bras., 20:452-458, 2002.

McINTYRE, D.S. Permeability measurements of soil crusts formed by raindrop impact. Soil Sci. Soc. Am. J., 85:185189,1958

MIRANDA, L.N.; MIRANDA, J.C.C.; REIN, T.A. \& GOMES, A.C. Utilização de calcário em plantio direto e convencional de soja e milho em Latossolo Vermelho. Pesq. Agropec. Bras., 40:563-572, 2005.

NELSON, P.N.; BALDOCK, J.A. \& OADES, J.M. Changes in dispersible clay content, organic carbon content, and electrolyte composition following incubation of sodic soil. Aust. J. Soil Res., 36:883-897, 1998.

NURMESNIEMI, H.; POYKIO, R.; PERAMAKI, P. \& KUOKKANEN, T. The use of a sequential leaching procedure for heavy metal fractionation in green liquor dregs from a causticizing process at a pulp mill. Chemosphere, 61:1475-1484, 2005.

TEDESCO, M.J.; VOLKWEISS, S.J. \& BOHNEN, H. Análises de solo, plantas e outros materiais. Porto Alegre, Universidade Federal do Rio Grande do Sul, 1995. 174p. (Boletim Técnico, 5)

REICHERT, J.M. \& NORTON, D.L. Fluidized bed bottom-ash effects on infiltration and erosion of swelling soils. Soil Sci. Soc. Am. J., 58:1483-1488, 1994.

SPARKS, D.L. Environmental soil chemistry. San Diego, Academic Press, 1995. 267p.

SUZUKI, A.; BASSO, C. \& KITAZAWA, I.H. O uso da lama de cal como corretivo da acidez do solo. Agropec. Catarinense, 4:9-11, 1991.

van OLPHEN, H. An introduction to clay colloid chemistry. 2.ed. New York, John Wiley \& Sons, 1977. 318p.

WALDEMAR, C.C. \& HERRERA, J. Avaliação do potencial de utilização do dregs e do grits como corretivo de acidez e fertilizantes na agricultura. In: CONGRESSO ANUAL DA ABCP, 19., São Paulo, 1986. Trabalhos técnicos... São Paulo, ABCP, 1986. p.12-18.

WEAST, R.C. Handbook of chemistry and physics. 53.ed. Cleveland, Chemical Rubber, 1972. 3100p. 